Check for updates

Cite this: Chem. Sci., 2019, 10, 8583

๑ All publication charges for this article have been paid for by the Royal Society of Chemistry

Received 11th May 2019

Accepted 16th July 2019

DOI: $10.1039 / \mathrm{c} 9 \mathrm{sc0} 02299 \mathrm{f}$

rsc.li/chemical-science

\section{Intramolecular azavinyl carbene-triggered rearrangement of furans $\dagger$}

\author{
Anton S. Makarov, ${ }^{a}$ Maxim G. Uchuskin (iD *a and A. Stephen K. Hashmi (D) *bc
}

An intramolecular rhodium-catalyzed reaction of 1-tosyl-1,2,3-triazoles with furans has been explored. The tosylimino functionality was found to play a significant chemical role participating in the subsequent domino-transformations of a key reaction intermediate. One of the reaction pathways leads to valuable 2-formyl- and 2-acetylpyridine building blocks, which could be obtained in one-pot starting from easily accessible (furan-2-ylmethyl)propargyl amines. An original method for the synthesis of highly functionalized indolizines from the obtained pyridines has been proposed.

\section{Introduction}

Ten years ago Gevorgyan and Fokin realized the colossal synthetic potential of metal-intercepted $\alpha$-diazoimine tautomers ${ }^{1}$ of sulfonyl triazoles, ${ }^{2}$ which were easily accessed through copper-catalyzed azide-alkyne cycloaddition (CuAAC). ${ }^{3}$ The resulting $\alpha$-iminocarbenoid species possess the characteristic reactivity of carbenes generated by denitrogenative decomposition of conventional diazo compounds; specifically, they undergo cheletropic reactions, $\mathrm{X}-\mathrm{H}$ and $\mathrm{C}-\mathrm{X}$ insertions, ylide formation or rearrangements (Fig. 1). ${ }^{4}$ However, the sulfonyl

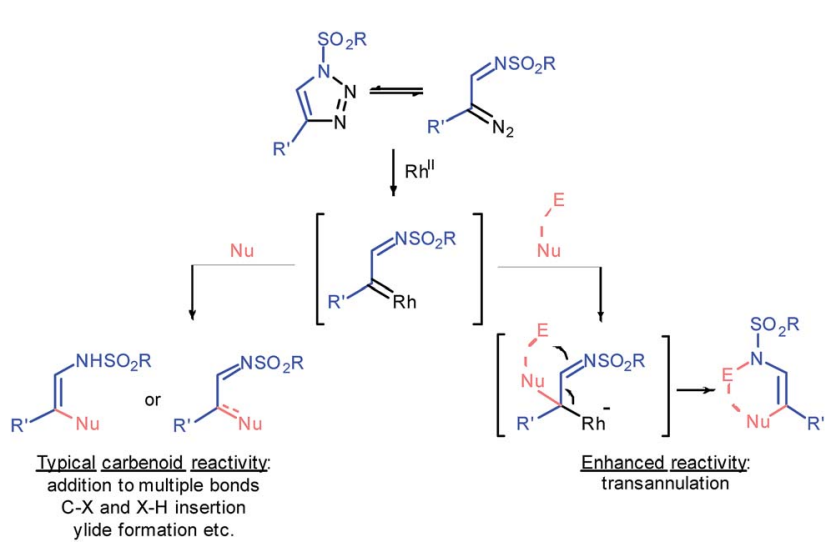

Fig. 1 General reactivity patterns of 1-sulfonyl-1,2,3-triazoles.

\footnotetext{
${ }^{a}$ Department of Chemistry, Perm State University, Bukireva 15, 614990 Perm, Russia. E-mail:mu@psu.ru

${ }^{b}$ Institut für Organische Chemie, Heidelberg University, Im Neuenheimer Feld 270, 69120 Heidelberg, Germany

${ }^{c}$ Chemistry Department, King Abdulaziz University, Jeddah 21589, Saudi Arabia. E-mail:hashmi@hashmi.de

$\uparrow$ Electronic supplementary information (ESI) available: Procedures, analytical data, and copies of ${ }^{1} \mathrm{H}$ and ${ }^{13} \mathrm{C}$ NMR spectra. See DOI: 10.1039/c9sc02299f
}

imine functionality exhibits untypical nucleophilicity, which allows the azavinyl carbenoids to undergo transannulations following the addition of a nucleophile to the carbene centre. ${ }^{5}$ Eventually, such an upgraded reactivity of rhodium transient azavinyl carbenoid species affords a high level of synthetic flexibility that is to some extent controlled by the nature of a reaction partner.

Furans represent nontrivial biomass-derived buildingblocks ${ }^{6}$ known for their propensity to undergo dearomatization $^{7,8}$ forming diverse carbo- ${ }^{9}$ and heterocyclic ${ }^{10}$ compounds under electrophilic conditions.

Understandably, furans were tested as nucleophiles in a reaction with carbenes derived from diazo compounds. While intermolecular reactions usually result in the formation of cyclopropane and dienone mixtures with poor regiocontrol, ${ }^{\mathbf{1 1}}$ intramolecular processes afford better chemoselectivity. In particular, the denitrogenative decomposition of various (furan2-yl)-tethered diazo compounds usually proceeds through the same spiro-intermediate, ${ }^{12,13}$ and yet leads to products with limited synthetic utility (Fig. 2a). In turn, decomposition of (furan-2-yl)-tethered 1-sulfonyl-1,2,3-triazoles would result in the formation of a common spiro-key intermediate that could be intercepted by an imino group, leading to compounds of type A (Fig. 2b, path I). Alternatively, the key intermediate might rearrange to azatriene $\mathbf{B}$ that could further be converted to a variety of nitrogen-containing heterocycles (Fig. 2b, path II). In either scenario there is the possibility for rapid accessing the molecular complexity from rather structurally simple starting materials.

To our surprise, we could not find any reports on intermolecular rearrangements of furans initiated by iminocarbene species derived from triazoles, although examples of denitrogenative decomposition of triazoles in the presence of a furanyl substituent within the same molecule are known. ${ }^{\mathbf{1 4 , 1 5}}$ In order to fill the methodological gap, we sought to explore the synthetic prospects of the aforementioned transformation. Very 
a
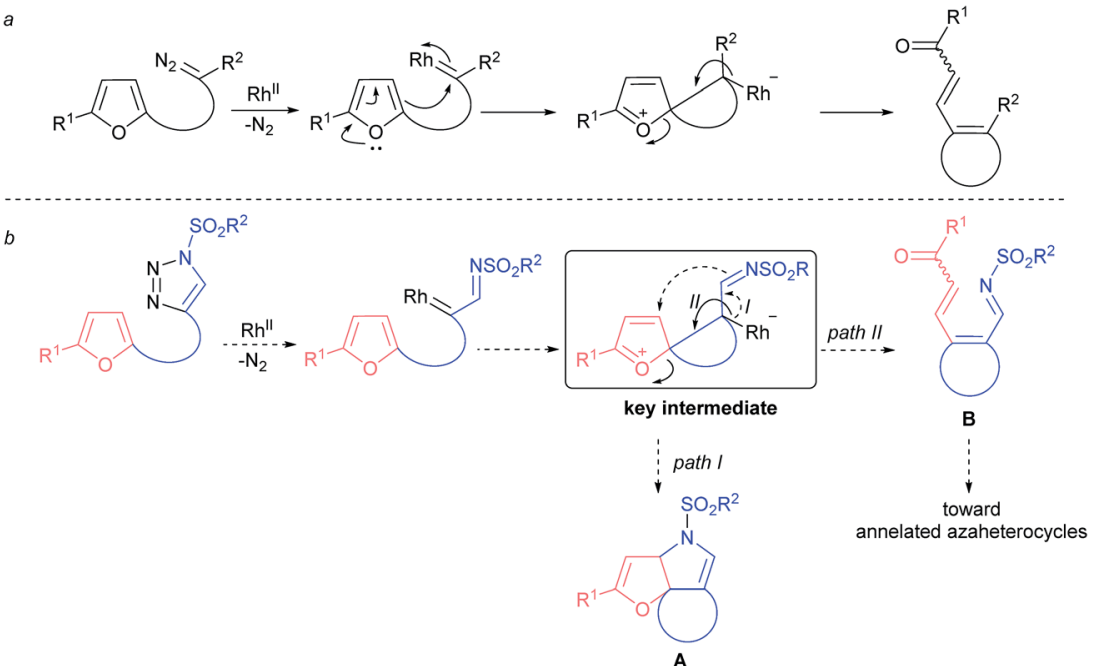

Fig. 2 Intramolecular rhodium carbenoid-triggered ring-opening of furans: (a) known reactivity; (b) concept for this work.

recently, Hashmi et al. described a synthetic method toward functionalized pyrroles based on the rearrangement of a furan ring in the gold(III)-catalyzed reaction of propargylfurfuryl amines with anthranyls. ${ }^{16}$ The reaction is believed to proceed through the intermediate formation of gold-stabilized iminocarbene species that attack the furan system followed by its dearomatization. The denitrogenative decomposition of furyltethered triazoles, in contrast, would provide regioisomeric iminocarbenes, which upon reaction with a furan ring could lead to the formation of valuable products of different architectures. Herein, we report our initial studies of intramolecular azavinyl carbene-triggered rearrangement of furans.

\section{Results and discussion}

Our exploratory studies commenced with triazole $\mathbf{2}$ as a model substrate, which was obtained via CuAAC from propargyl amine 1a (Scheme 1). Treatment of triazole 2 with rhodium acetate dimer in chloroform at $50{ }^{\circ} \mathrm{C}$ led to a full conversion of the starting material within $5 \mathrm{~h}$. Careful analysis of the crude reaction mixture revealed that the main component among the formed products appeared to be dihydropyridine 3 . However, all attempts to isolate compound 3 by column chromatography on silica gel failed; the only product detected was 2-acetylpyridine 4a. The same outcome was observed when the reaction mixture was treated with a base. Apparently, the formation of 2-acetylpyridine $\mathbf{4 a}$ resulted from $6 \pi$-azaelectrocyclization ${ }^{\mathbf{1 7}}$ of initially formed dihydropyrrole II followed by aromatization through elimination of sulfinate. ${ }^{18}$ Stimulated by the high synthetic value of 2-acylpyridines as intermediates in medicinal $^{19}$ and material ${ }^{20}$ chemistry, we decided to study the discovered transformation in more detail.

The optimization of reaction conditions revealed that toluene was the solvent of choice for the formation of dihydropyridine 3a (Table 1, entry 1; for more details, see the $\operatorname{ESI}_{\dagger} \dagger$ ). Further screening of rhodium(II) sources led us to identify $\mathrm{Rh}_{2}$ (OOct $)_{4}$ as the optimal catalyst for the first cascade transformation (entries 2-5). As compound 3 appeared to be quite unstable, we continued tuning the reaction conditions towards final acetylpyridine $4 \mathrm{a}$ in a one-pot mode.

After some experiments, we found that addition of two equivalents of $\mathrm{Et}_{3} \mathrm{~N}$ resulted in the clean transformation of dihydropyridine $\mathbf{3 a}$ into its unsaturated derivative $\mathbf{4 a}$ (entry 8).

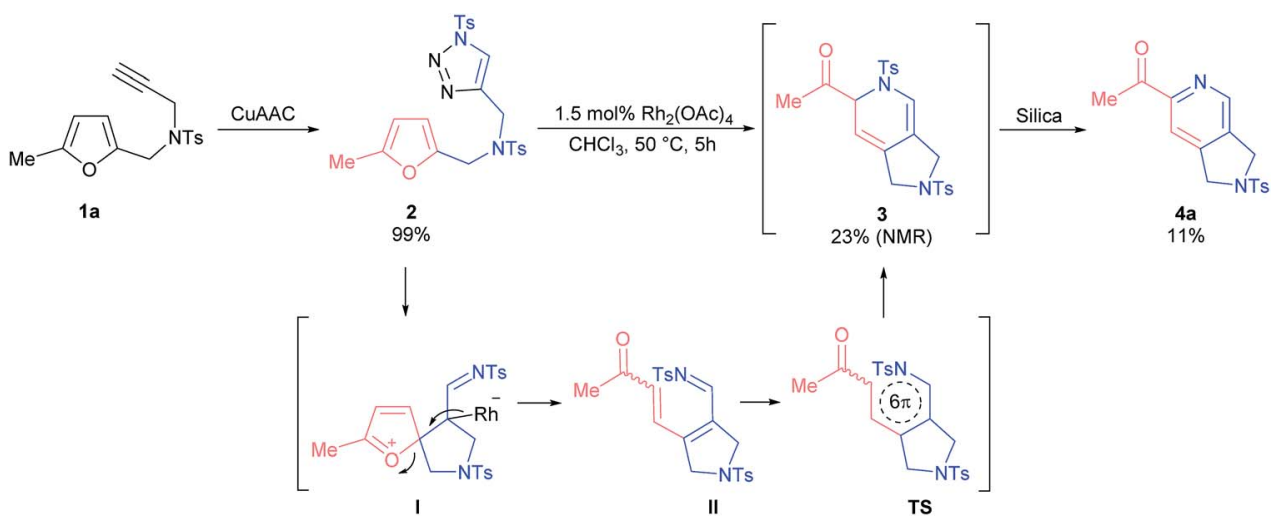

Scheme 1 Initial results. 
Table 1 Optimization of the reaction conditions ${ }^{a}$

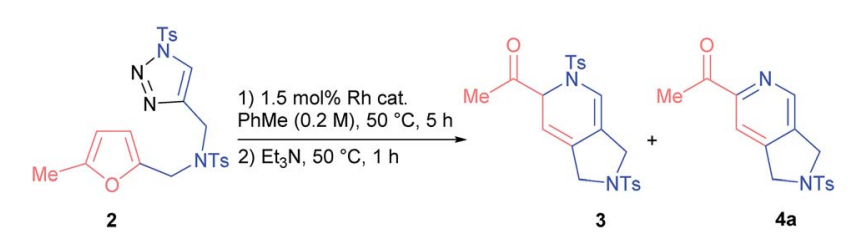

\begin{tabular}{lllll}
\hline Entry & $\mathrm{Rh}$ cat. & $\begin{array}{l}\mathrm{Et}_{3} \mathrm{~N} \\
\text { (equiv.) }\end{array}$ & Yield of $\mathbf{3}^{b}, \%$ & Yield of $\mathbf{4 a}^{b}, \%$ \\
\hline 1 & $\mathrm{Rh}_{2}(\mathrm{OAc})_{4}$ & - & 55 & Trace \\
2 & $\mathrm{Rh}_{2}($ OCOTr) & - & 62 & Trace \\
3 & $\mathrm{Rh}_{2}(\text { OPiv })_{4}$ & - & 63 & Trace \\
4 & $\mathrm{Rh}_{2}(\text { OHex })_{4}$ & - & 75 & Trace \\
5 & $\mathrm{Rh}_{2}(\text { OOct })_{4}$ & - & $90^{c}$ & Trace \\
6 & $\mathrm{Rh}_{2}$ (OOct $)_{4}$ & $(1)$ & Trace & $\mathbf{7 9}^{c}$ \\
7 & $\mathbf{R h}_{2}$ (OOct $)_{4}$ & $\mathbf{( 2 )}$ & Trace & $\mathbf{9 3}^{c}(\mathbf{9 0})^{d}$
\end{tabular}

${ }^{a}$ General considerations: reactions were performed on a $0.05 \mathrm{mmol}$ scale of 2 under dinitrogen; freshly distilled and degassed toluene and $\mathrm{Et}_{3} \mathrm{~N}$ were used. ${ }^{b} \mathrm{NMR}$ yields with $\mathrm{CH}_{2} \mathrm{Br}_{2}$ as an internal standard. ${ }^{c}$ Reaction time $-10 \mathrm{~h} .{ }^{d}$ Reaction was performed on a $0.5 \mathrm{mmol}$ scale; yield of the isolated product is given in parentheses; reaction time for the first step $-16 \mathrm{~h}$.

With the aim of establishing a convenient synthetic method towards 2-acylpyridines, we integrated the CuAAC step into a single one-pot protocol starting from propargyl amines 1. To our delight, the addition of an extra step had almost no effect on the outcome of the model reaction; the yield of pyridine 4a was $88 \%$ (Scheme 2). Moreover, on a gram-scale the method afforded pyridine $4 \mathrm{a}$ in comparable yield with the use of only 0.5 mol\% of rhodium catalyst (see the ESI $\dagger$ for details).

Following the optimization studies, we sought to study the influence of various substituents at different positions of the starting material on the reaction outcome. Substituted propargyl amines 1a-I were screened first (Table 2). Bromo and nitro substituents in other tested sulfonyl protection groups were tolerated well under the optimized conditions (compounds $\mathbf{4 b}$ and c). It was possible to introduce substituents at propargylic (compounds 4d and e) and furfuryl positions (compound $\mathbf{4 g}$ ) of the starting material, although the overall transformation resulted in lower yields of the respective products, probably due to steric reasons. Indeed, more bulky substituents at either position prevented the furan from being attacked by a carbene centre in an initial step: in the cases of starting materials $\mathbf{1 f}$ and 1h we observed the formation of corresponding triazoles that decomposed over time. After additional tuning of reaction

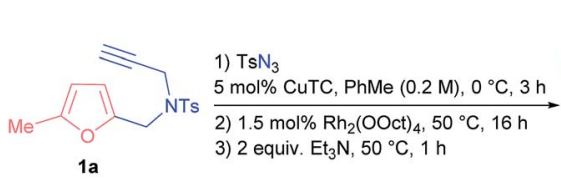

Scheme 2 One-pot synthesis of pyridine $4 a$.
Table 2 Scope of furfuryl amines ${ }^{a}$
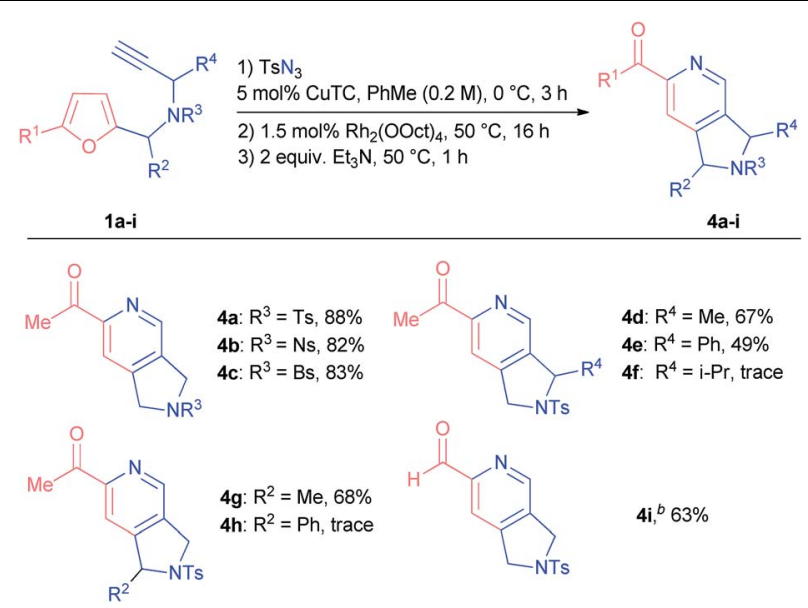

${ }^{a}$ General considerations: reactions were performed on a $0.5 \mathrm{mmol}$ scale of propargyl amines 1 under dinitrogen; stepwise addition of catalysts and reagents. For more details, see the ESI. ${ }^{b}$ Second step $-1 \mathrm{~h}$ at 75 ${ }^{\circ} \mathrm{C}$ and then third step $-1 \mathrm{~h}$ at $75{ }^{\circ} \mathrm{C}$.

parameters, we were also able to obtain 2-formylpyridine $\mathbf{4 i}$ in $63 \%$ yield.

Next, we studied substrates with an extended tether that linked the triazole fragment and a furan ring. Thus, homopropargylamine $\mathbf{5}$ reacted smoothly under slightly altered reaction conditions to provide tetrahydronaphthiridine 6 (78\%) (Scheme 3).

When we tested homofurfurylamine 7 , which was forced to react under quite harsh conditions, we observed the formation of pyrrole 8 as well as dihydropyridine 9 (Scheme 4). Presumably, pyrrole $\mathbf{8}$ was the product of an alternative reaction where initially formed spiro-intermediate III was trapped intermolecularly with the imino group followed by base-induced ringopening of dihydrofuran intermediate $\mathbf{V}$ (route a). In turn, dihydropyridine 9 was formed via $6 \pi$-azaelectrocyclization of azatriene IV following the ring-opening of initial intermediate III (route b). Evidently, the nature of the tether modulates the geometry of an intermediate III at such an elevated reaction temperature, so that it can demonstrate alternative reactivity.

Dihydropyridine 9 was found to be more stable than its analogue, dihydropyridine 3 . Conversion of compound 9 into the corresponding pyridine 10 required much harsher reaction conditions as well (Scheme 5).

We examined the reactivity of propargyl ethers 11 that were found to be more reactive than related amines 1 (Table 3).
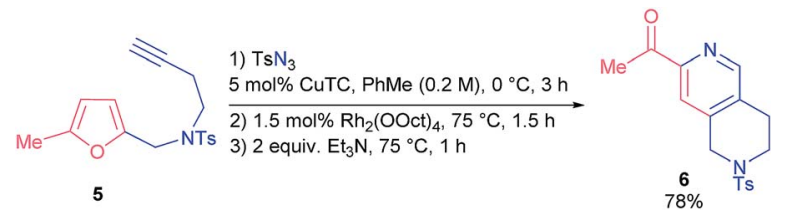

Scheme 3 Synthesis of tetrahydronaphthiridine 6 . 


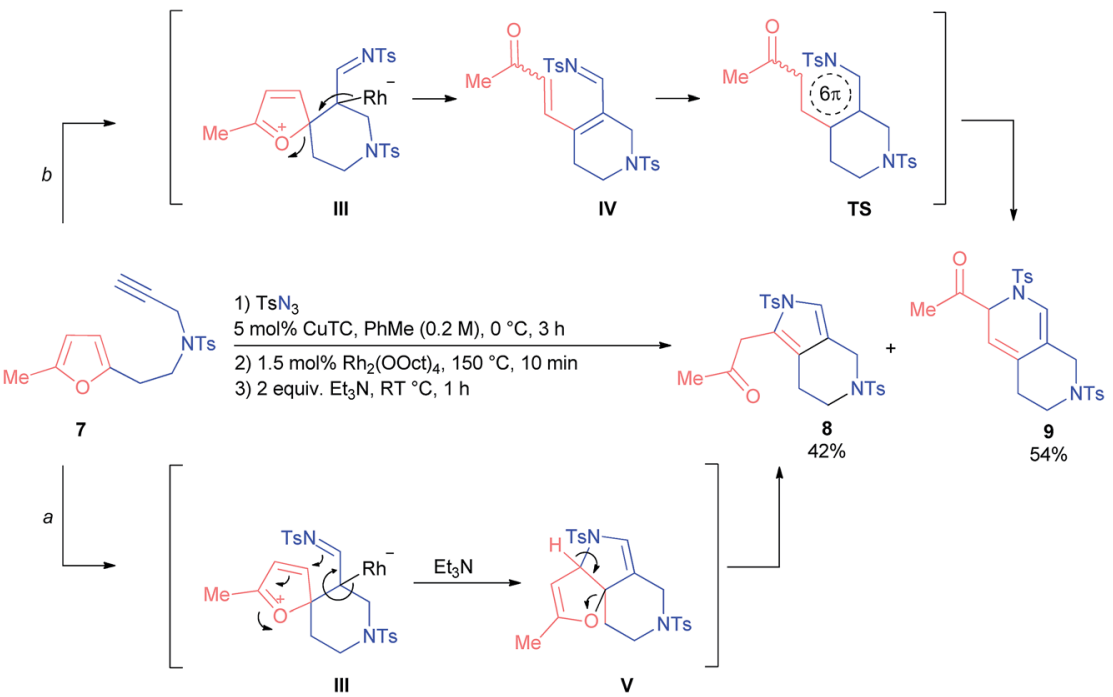

Scheme 4 Divergent reactivity of homofurfurylamine 7.

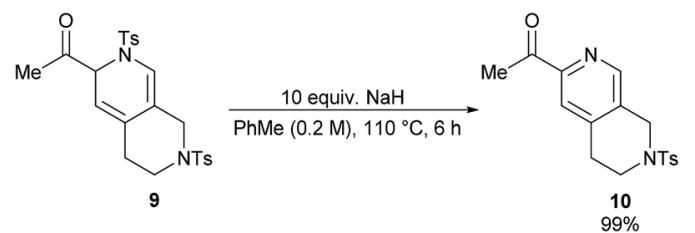

Scheme 5 Synthesis of tetrahydronaphthiridine 10

Consequently, they had to be converted under milder conditions in order to avoid undesired side reactions.

Generally, substrates 11 afforded corresponding products 12 in higher yields, even those bearing bulky substituents in the furfuryl position (products 12c and d). Noteworthily, 2-formylpyridine 12e was as well obtained in practical yield.

The reaction of propargyl ethers with voluminous substituents at C(5) of a furan ring (compounds 11f and $\mathbf{g}$ ) stopped at

Table 3 Scope of furfuryl ethers ${ }^{a}$
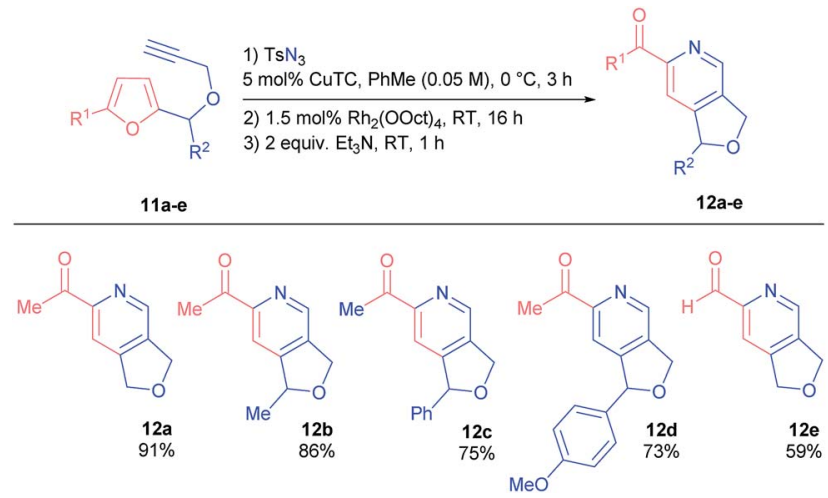

${ }^{a}$ General considerations: reactions were performed on a $0.5 \mathrm{mmol}$ scale of a propargyl ether $\mathbf{1 1}$ under dinitrogen; stepwise addition of catalysts and reagents. For more details, see the ESI. the formation of $Z$-azatrienes 13a and $\mathbf{b}$, the products of the ring-opening of the initial spiro-intermediates (Scheme 6). Likely, bulky groups obstruct the electrocyclization of the respective azatrienes. All attempts to force the reactions only led to $Z$-to- $E$ isomerization of the $\alpha, \beta$-unsaturated ketone moiety.

Finally, we probed propargyl ester 14 with a lengthened linker. Under various conditions the only product we always detected was the very unstable enol ether 15, which, apparently, was formed through 1,2-shift of a hydride to a carbene atom. Eventually, we found conditions that provided a nearly quantitative yield of compound $\mathbf{1 5}$ (Scheme 7).

It is known that 1,2-hydride shifts often follow the denitrogenative decomposition of 4-alkyltriazoles, which reduces the yields of the target compounds. ${ }^{21}$ Possibly, this competing reaction also affects the outcome of the studied processes. It seems that the observed sigmatropic rearrangement is a kinetically controlled reaction in the case of substrate 14: both the longer tether and higher proclivity of the oxygen atom to donate its electron pair (compared to the NTs group) make enol 15 a predominant product.

2-Acylpyridines are known to be largely used for the synthesis $^{22}$ of indolizines, indolizidines and their close structural analogues, which represent core frameworks for the vast number of alkaloids and biologically active compounds. ${ }^{23} \mathrm{We}$ attempted to further extend the application of the obtained

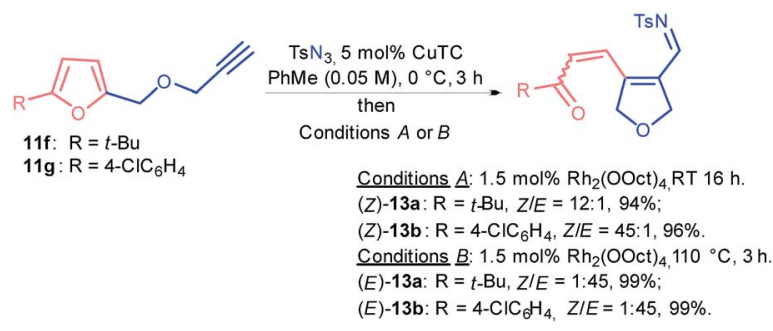

Scheme 6 Reactivity of propargyl ethers $11 \mathrm{f}$ and $\mathrm{g}$. 


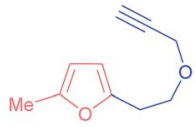

14

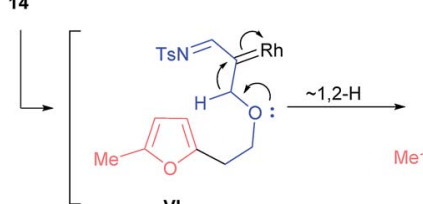

VI
1) $\mathrm{TsN}_{3}$

$5 \mathrm{~mol} \%$ CuTC, PhMe $(0.05 \mathrm{M}), 0^{\circ} \mathrm{C}, 3 \mathrm{~h}$

2) $1.5 \mathrm{~mol} \% \mathrm{Rh}_{2}(\mathrm{OOCt})_{4}, 75^{\circ} \mathrm{C}, 10 \mathrm{~min}$

3) 2 equiv. $\mathrm{Et}_{3} \mathrm{~N}, 75^{\circ} \mathrm{C}, 10 \mathrm{~min}$

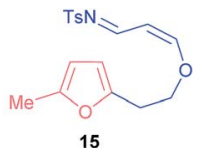

15
Scheme 7 Reaction of propargyl ether 15

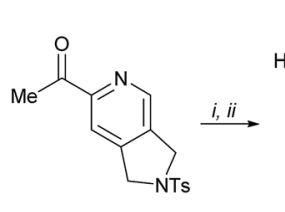

$4 a$

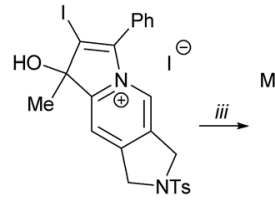

16

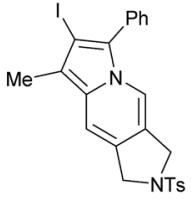

17
Scheme 8 Synthesis of indolizine 17. Reaction conditions: (i) 1.5 equiv. (phenylethynyl)lithium, 3 equiv. $\mathrm{LiBr}, \mathrm{Et}_{2} \mathrm{O} / \mathrm{PhH}, \mathrm{RT}$, and $15 \mathrm{~h}$; (ii) 1.5 equiv. $\mathrm{I}_{2}, \mathrm{DCM}, \mathrm{RT}$, and $5 \mathrm{~h}$ (93\% over 2 steps); (iii) 2 equiv. $\mathrm{NaBH}_{4}$, $\mathrm{MeOH}, \mathrm{RT}$, and 30 min (99\%).

products for the synthesis of functionalized indolizines through trivial functional group manipulations. The addition of (phenylethynyl)lithium to a carbonyl group of 2-acetylpyridine $\mathbf{4 a}$ followed by treatment of the resulting propargyl alcohol with molecular iodine afforded indolizinium salt 16 in excellent yield (Scheme 8). The reduction of compound 16 with sodium borohydride directly led to 2-iodoindolizine 17 through the simultaneous dehydration of intermediate dihydroindolizinol. To the best of our knowledge, this synthetic pathway has not been reported previously.

\section{Conclusions}

In conclusion, we studied some aspects of previously non-reported intramolecular reactions of azavinyl rhodium carbenoid species with furans. Our findings enabled us to develop a straightforward one-pot protocol toward fused 2-acetyl- and 2formylpyridines from easily accessible biomass-derived furan building-blocks. We demonstrated that the obtained pyridines could be utilized for the synthesis of highly functionalized indolizines through the original high-yielding protocol. Additionally, we found that rearrangement of furans triggered by rhodium iminocarbenes could possibly proceed via two distinct pathways, thereby providing different heterocyclic frameworks. Our initial results highlight that intermolecular rearrangement of furyl triazoles has high potential as a practical tool for the design of various heterocyclic compounds. Further aspects of the discovered transformations will be reported in due course.

\section{Conflicts of interest}

There are no conflicts to declare.

\section{Acknowledgements}

We thank the Ministry of Science and Higher Education of The Russian Federation (project No. 4.5371.2017/8.9) and Russian Foundation for Basic Research (grant No. 19-43-590007 p_a) for the financial support. ASM thanks the Ministry of Science and Higher Education of The Russian Federation for The President academic mobility scholarship.

\section{Notes and references}

1 O. Dimroth, Justus Liebigs Ann. Chem., 1909, 364, 183.

2 T. Horneff, S. Chuprakov, N. Chernyak, V. Gevorgyan and V. V. Fokin, J. Am. Chem. Soc., 2008, 130, 14972.

3 (a) M. S. Singh, S. Chowdhury and S. Koley, Tetrahedron, 2016, 72, 5257; (b) L. Liang and D. Astruc, Coord. Chem. Rev., 2011, 255, 2933; (c) J. E. Hein and V. V. Fokin, Chem. Soc. Rev., 2010, 39, 1302.

4 (a) Y. Xia, D. Qiu and J. Wang, Chem. Rev., 2017, 117, 13810; (b) N. R. Candeias, R. Paterna and P. M. Gois, Chem. Rev., 2016, 116, 2937; (c) X. Zhao, Y. Zhang and J. Wang, Chem. Commun., 2012, 48, 10162; (d) H. M. Davies and J. R. Denton, Chem. Soc. Rev., 2009, 38, 3061; (e) H. M. Davies and J. R. Manning, Nature, 2008, 451, 417.

5 (a) Y. Li, H. Yang and H. Zhai, Chem.-Eur. J., 2018, 24, 12757; (b) Y. Jiang, R. Sun, X. Y. Tang and M. Shi, Chem.-Eur. J., 2016, 22, 17910; (c) H. M. Davies and J. S. Alford, Chem. Soc. Rev., 2014, 43, 5151; (d) P. Anbarasan, D. Yadagiri and S. Rajasekar, Synthesis, 2014, 46, 3004; (e) B. Chattopadhyay and V. Gevorgyan, Angew. Chem., Int. Ed., 2012, 51, 862; Angew. Chem., 2012, 124, 886.

6 (a) Z. Zhang and G. W. Huber, Chem. Soc. Rev., 2018, 47, 1351; (b) F. A. Kucherov, L. V. Romashov, K. I. Galkin and V. P. Ananikov, ACS Sustainable Chem. Eng., 2018, 6, 8064; (c) M. Besson, P. Gallezot and C. Pinel, Chem. Rev., 2014, 114, 1827; (d) R. J. van Putten, J. C. van der Waal, E. de Jong, C. B. Rasrendra, H. J. Heeres and J. G. de Vries, Chem. Rev., 2013, 113, 1499.

7 A. T. Balaban, D. C. Oniciu and A. R. Katritzky, Chem. Rev., 2004, 104, 2777.

8 S. P. Roche and J. A. Porco Jr, Angew. Chem., Int. Ed., 2011, 50, 4068; Angew. Chem., 2011, 123, 4154.

9 (a) N. Sun, X. Xie, H. Chen and Y. Liu, Chem.-Eur. J., 2016, 22, 14175; (b) D. Lebœuf, M. Gaydou, Y. Wang and A. M. Echavarren, Org. Chem. Front., 2014, 1, 759; (c) Y. Chen, L. Wang, N. Sun, X. Xie, X. Zhou, H. Chen, Y. Li and Y. Liu, Chem.-Eur. J., 2014, 20, 12015; (d) N. Huguet, D. Leboeuf and A. M. Echavarren, Chem.-Eur. J., 2013, 19, 6581.

10 (a) E. Y. Zelina, T. A. Nevolina, L. N. Sorotskaja, D. A. Skvortsov, I. V. Trushkov and M. G. Uchuskin, J. Org. Chem., 2018, 83, 11747; (b) Y. Yang, C. Fei, K. Wang, B. Liu, D. Jiang and B. Yin, Org. Lett., 2018, 20, 2273; (c) A. S. Makarov, M. G. Uchuskin and V. Gevorgyan, J. Org. Chem., 2018, 83, 14010; (d) J. Guo, X. Xu, Q. Xing, Z. Gao, J. Gou and B. Yu, Org. Lett., 2018, 20, 7410; (e) A. S. Hashmi, M. Rudolph, J. Huck, W. Frey, J. W. Bats and 
M. Hamzic, Angew. Chem., Int. Ed., 2009, 48, 5848; Angew. Chem., 2009, 121, 5962.

11 (a) V. Lehner, H. M. L. Davies and O. Reiser, Org. Lett., 2017, 19, 4722; (b) M. Marinozzi, M. C. Fulco, L. Amori, M. Fiumi and R. Pellicciari, Tetrahedron, 2009, 65, 7092; (c) J. Hansen, B. Li, E. Dikarev, J. Autschbach and H. M. Davies, J. Org. Chem., 2009, 74, 6564; (d) S. J. Hedley, D. L. Ventura, P. M. Dominiak, C. L. Nygren and H. M. Davies, J. Org. Chem., 2006, 71, 5349; (e) A. Caballero, M. M. Diaz-Requejo, S. Trofimenko, T. R. Belderrain and P. J. Perez, J. Org. Chem., 2005, 70, 6101. 12 (a) H. M. L. Davies and R. L. Calvo, Tetrahedron Lett., 1997, 38, 5623; (b) E. Wenkert, R. Decorzant and F. Näf, Helv. Chim. Acta, 1989, 72, 756; (c) A. Padwa, T. J. Wisnieff and E. J. Walsh, J. Org. Chem., 1989, 54, 299; (d) E. Wenkert, M. Guo, F. Pizzo and K. Ramachandran, Helv. Chim. Acta, 1987, 70, 14298; (e) A. Padwa, T. J. Wisnieff and E. J. Walsh, J. Org. Chem., 1986, 51, 5036.

13 For examples of related intermolecular reactions of furans with a carbenoid generated from a non-diazo precursor, see J. M. Yang, X. Y. Tang and M. Shi, Chem.-Eur. J., 2015, 21, 4534.

14 (a) Z. F. Xu, X. Yu, D. Yang and C. Y. Li, Org. Biomol. Chem., 2017, 15, 3161; (b) R. Sun, Y. Jiang, X. Y. Tang and M. Shi, Chem.-Eur. J., 2016, 22, 5727; (c) S. Shin, J. Y. Son, C. Choi, S. Kim and P. H. Lee, J. Org. Chem., 2016, 81, 11706; (d) B. Seo, W. H. Jeon, J. Kim, S. Kim and P. H. Lee, J. Org. Chem., 2015, 80, 722; (e) Y. Jiang, X. Y. Tang and M. Shi, Chem. Commun., 2015, 51, 2122; (f) Y. S. Zhang, X. Y. Tang and M. Shi, Chem. Commun., 2014, 50, 15971.

15 For key examples of intermolecular reactions of furans with azavinyl carbenoids, see (a) Y. Funakoshi, T. Miura and M. Murakami, Org. Lett., 2016, 18, 6284; (b) B. T. Parr, S. A. Green and H. M. Davies, J. Am. Chem. Soc., 2013, 135, 4716.

16 Z. Zeng, H. Jin, M. Rudolph, F. Rominger and A. S. K. Hashmi, Angew. Chem., Int. Ed., 2018, 57, 16549; Angew. Chem., 2018, 130, 16787.
17 (a) D. F. Vargas, E. L. Larghi and T. S. Kaufman, Eur. J. Org. Chem., 2018, 40, 5605; (b) A. Patel, J. R. Vella, Z. X. Ma, R. P. Hsung and K. N. Houk, J. Org. Chem., 2015, 80, 11888; (c) M. L. Meketa, S. M. Weinreb, Y. Nakao and N. Fusetani, J. Org. Chem., 2007, 72, 4892.

18 (a) X. Ma, L. Liu, J. Wang, X. Xi, X. Xie and H. Wang, J. Org. Chem., 2018, 83, 14518; (b) H. Dai, S. Yu, W. Cheng, Z. F. Xu and C. Y. Li, Chem. Commun., 2017, 53, 6417.

19 (a) B. M. Zeglis, V. Divilov and J. S. Lewis, J. Med. Chem., 2011, 54, 2391; (b) D. R. Richardson, D. S. Kalinowski, V. Richardson, P. C. Sharpe, D. B. Lovejoy, M. Islam and P. V. Bernhardt, J. Med. Chem., 2009, 52, 1459; (c) J. Easmon, G. Purstinger, K. S. Thies, G. Heinisch and J. Hofmann, J. Med. Chem., 2006, 49, 6343.

20 (a) M. Raeisi, K. Kotturi, I. Del Valle, J. Schulz, P. Dornblut and E. Masson, J. Am. Chem. Soc., 2018, 140, 3371; (b) M. Wang, C. Wang, X. Q. Hao, X. Li, T. J. Vaughn, Y. Y. Zhang, Y. Yu, Z. Y. Li, M. P. Song, H. B. Yang and X. Li, J. Am. Chem. Soc., 2014, 136, 10499; (c) C. Wang, X.-Q. Hao, M. Wang, C. Guo, B. Xu, E. N. Tan, Y.-Y. Zhang, Y. Yu, Z.-Y. Li, H.-B. Yang, M.-P. Song and X. Li, Chem. Sci., 2014, 5, 1221; (d) S. Perera, X. Li, M. Guo, C. Wesdemiotis, C. N. Moorefield and G. R. Newkome, Chem. Commun., 2011, 47, 4658.

21 (a) Y. Z. Zhao, H. B. Yang, X. Y. Tang and M. Shi, Chem.-Eur. J., 2015, 21, 3562; (b) F. Medina, C. Besnard and J. Lacour, Org. Lett., 2014, 16, 3232.

22 (a) S. T. Heller, T. Kiho, A. R. Narayan and R. Sarpong, Angew. Chem., Int. Ed., 2013, 52, 11129; Angew. Chem., 2013, 125, 11335; (b) I. Kim, J. Choi and G. H. Lee, Synlett, 2008, 1243; (c) B. Yan, Y. Zhou, H. Zhang, J. Chen and Y. Liu, J. Org. Chem., 2007, 72, 7783; (d) C. R. Smith, E. M. Bunnelle, A. J. Rhodes and R. Sarpong, Org. Lett., 2007, 9, 1169.

23 (a) B. Sadowski, J. Klajn and D. T. Gryko, Org. Biomol. Chem., 2016, 14, 7804; (b) J. P. Michael, Nat. Prod. Rep., 2008, 25, 139; (c) J. P. Michael, Nat. Prod. Rep., 2005, 22, 603. 